\title{
Vibrated concrete vs. self-compacting concrete: comparison of fracture mechanics properties
}

\author{
Sara Korte ${ }^{1,2}$ a , Veerle Boel ${ }^{1,2, b}$, Wouter De Corte ${ }^{1,2, c}$ and Geert De Schutter ${ }^{2, d}$ \\ ${ }^{1}$ Department of Construction, Faculty of Applied Engineering Sciences, University College Ghent, \\ Valentin Vaerwyckweg 1, 9000 Ghent, Belgium \\ ${ }^{2}$ Department of Structural Engineering, Faculty of Engineering Sciences and Architecture, Ghent \\ University, Technologiepark-Zwijnaarde 904, 9000 Ghent, Belgium \\ a'Sara.Korte@hogent.be, 'eerle.Boel@hogent.be, 'Wouter.DeCorte@hogent.be, \\ 'Geert.DeSchutter@Ugent.be
}

Keywords: self-compacting concrete, cracking behaviour, fracture mechanics, three-point bending test, wedge-splitting test.

\begin{abstract}
This study focuses on the fracture mechanics aspect of self-compacting concrete, compared to vibrated concrete. The most commonly used experiments to investigate the toughness and cracking behaviour of concrete are the three-point bending test (3PBT) on small, notched beams, and the wedge-splitting test (WST) on cubic samples with guiding groove and starter notch. From the resulting P-CMOD curves (applied load versus crack mouth opening displacement), different fracture parameters, such as fracture energy and fracture toughness, can be extracted. Moreover, using inverse analysis, the $\sigma-\mathrm{w}$ relationship (tensile stress versus crack width) can be derived. This paper lists the results of a series of tests on samples, made of VC, SCC of equal strength, and SCC with identical w/c factor. Subsequently, a comparison of the mechanical characteristics is made, revealing important differences regarding several fracture parameters.
\end{abstract}

\section{Introduction}

Extensive research has been carried out on fresh, hardened and transport properties, as well as on durability aspects [1-3] of SCC, showing that the substantially different composition, opposed to VC, sometimes causes an altered mechanical behaviour. The specific mix design of SCC, which guarantees its self-compacting ability in fresh state, inevitably influences the performance of the hardened concrete. For instance, the higher content of fine particles (e.g. by adding fillers) affects the whole microstructure, making the interfacial transition zone of SCC stronger and consequently increasing the compressive and tensile strength, compared to VC with the same w/c ratio [1]. Furthermore, the reduction in the amount of coarse aggregates in SCC contributes to a lower value of Young's modulus, when compared to VC of equal strength [1]. Considering these abovementioned findings, a distinct fracture behaviour can be expected, since it is both, the strength of the cement paste, and the location and size of the aggregates that play an important role in the crack propagation phenomenon $[4,5]$.

\section{Experimental Program}

Mixtures. Three different concrete mixtures were used in this experiment; VC, SCC1 and SCC2. $\mathrm{VC}$ is a traditional, vibrated concrete type and serves as a reference batch for comparison with a self-compacting concrete with similar strength (SCC1), and another SCC with equal w/c ratio (SCC2). Apart from the 3PBT beams and the WST samples, several control specimens were cast from each batch in order to determine the compressive strength. After curing for 24 hours, these standardized cubes (side $150 \mathrm{~mm}$ ) and cylinders (diameter $150 \mathrm{~mm}$, height $300 \mathrm{~mm}$ ) were demoulded and then stored under water at $20 \pm 2{ }^{\circ} \mathrm{C}$. They were tested at the age of 28 days, according to EN 
12390-3. Table 1 contains the results, which clearly demonstrate that VC and SCC1 have the same strength (as was aimed for), while SCC2 must be classified in a higher strength class.

Specimens. The exact dimensions of the 3PBT specimens are depicted in Fig. 1a. After curing for 24 hours and subsequent demoulding, the beams were stored in lab conditions. Approximately two days before testing, the $3 \mathrm{~mm}$ wide notch was made using a wet diamond saw. The depth of the saw cut (a) is chosen 33mm, since RILEM TC89-FTM (1991) recommends a notch length of 1/3rd of the beam's height $(\mathrm{h})$ in order to ensure the location of crack initiation.

Based on the geometry and dimensions in Löfgren et al. [6], the WST samples were cast in a standard cube mould (side $150 \mathrm{~mm}(\mathrm{~d}, \mathrm{~h})$ ) into which a wooden rod was placed to obtain the guiding groove (see Fig. 1b). The specimens underwent the same curing -, demoulding -, and storage procedure as the 3PBT beams and again, two days prior to testing, a $3 \mathrm{~mm}$ wide and $33 \mathrm{~mm}$ long (a) starter notch was cut by wet diamond sawing.

(a)

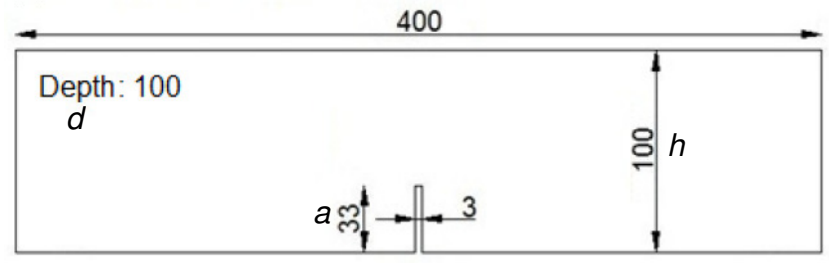

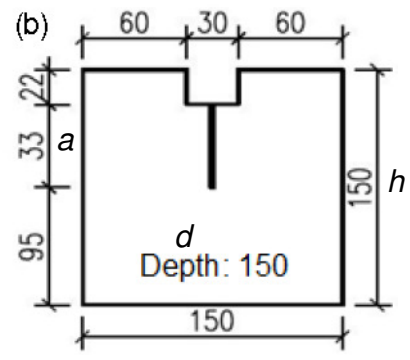

Fig. 1. Geometry and dimensions ( $\mathrm{mm}$ ) of specimens for a) 3PBT b) WST

Test procedure. A static, vertical load $\left(\mathrm{F}_{\mathrm{v}}\right)$ was applied, using an hydraulic, computer controlled, compression test device. As to the WST, this vertical load was converted into two horizontal splitting forces $\left(\mathrm{F}_{\mathrm{sp}}\right)$ by means of a wedge, moving between two roller bearings. Fig. 2 shows the test setup for both, the 3PBT and the WST. During the tests, the CMOD was set to increase with a uniform rate of $0.0005 \mathrm{~mm} / \mathrm{s}$, while $\mathrm{F}_{\mathrm{v}}$ was continuously registered. Moreover, the CMOD was constantly measured by a clip gauge, fixed at the notch end.

(a)

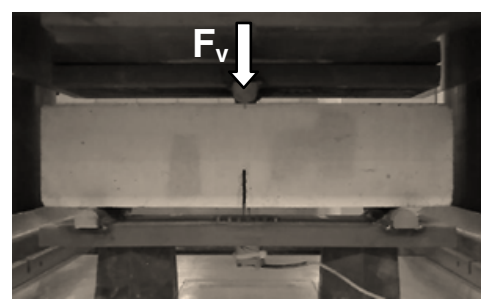

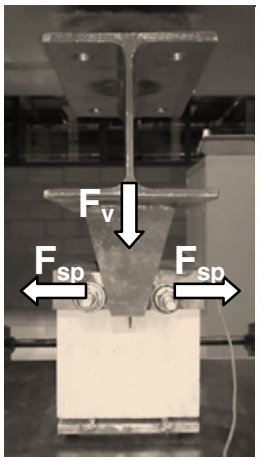

Fig. 2. Test setup for a) 3PBT b) WST

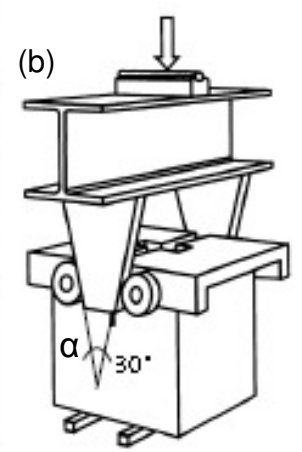

\section{Calculations}

From the resulting load-CMOD curves, the size-dependent fracture energy $\mathrm{G}_{\mathrm{F}}$ - which represents the energy release during the cracking process - was calculated by Eq. 1. Furthermore, using the $G_{F}$ value, the fracture toughness $\mathrm{K}_{\mathrm{Ic}}$ - an indicator for the material's brittleness - was determined using Eq. 2.

$$
\begin{aligned}
G_{F} & =\frac{1}{(h-a) d} \int F d(C M O D) \\
K_{I c} & =\sqrt{E \cdot G_{F}} \quad \text { (with E = Young's modulus) }
\end{aligned}
$$


In order to obtain the so called softening curve or stress-crack opening relationship, the experimental results were put into numerical computation software. Using inverse analysis, the stresses in cracked state are calculated as a function of the crack width (w) and the uniaxial tensile strength $\left(\mathrm{f}_{\mathrm{t}}\right)$, resulting in a bilinear $\sigma-\mathrm{w}$ graph.

\section{Results and Discussion}

Table 1. Properties of VC, SCC1 and SCC2

\begin{tabular}{llll}
\hline & VC & SCC1 & SCC2 \\
\hline $\mathrm{f}_{\mathrm{cm}}[\mathrm{MPa}]$ & $53.4 \pm 2.3$ & $53.9 \pm 7.9$ & $65.0 \pm 8.3$ \\
$\mathrm{f}_{\mathrm{c}, \mathrm{cub}, \mathrm{m}}[\mathrm{MPa}]$ & $54.3 \pm 4.7$ & $54.6 \pm 12.1$ & $63.8 \pm 4.8$ \\
\hline 3PBT & $\mathbf{V C}$ & $\mathbf{S C C 1}$ & $\mathbf{S C C 2}$ \\
\hline $\mathrm{F}_{\max }[\mathrm{kN}]$ & $6.11 \pm 0.48$ & $6.94 \pm 0.87$ & $6.12 \pm 0.49$ \\
$\mathrm{G}_{\mathrm{F}}[\mathrm{N} / \mathrm{m}]$ & $191 \pm 22$ & $164 \pm 39$ & $201 \pm 32$ \\
$\mathrm{~K}_{\mathrm{IC}}\left[\mathrm{x} 10^{6} \mathrm{~N} / \mathrm{m}^{3 / 2}\right]$ & $2.70 \pm 0.15$ & $2.61 \pm 0.28$ & $2.90 \pm 0.23$ \\
\hline $\mathbf{W S T}$ & $\mathbf{V C}$ & $\mathbf{S C C 1}$ & $\mathbf{S C C 2}$ \\
\hline $\mathrm{F}_{\mathrm{sp}, \max }[\mathrm{kN}]$ & $10.45 \pm 0.81$ & $10.37 \pm 1.18$ & $9.99 \pm 0.88$ \\
$\mathrm{G}_{\mathrm{F}}[\mathrm{N} / \mathrm{m}]$ & $98 \pm 10$ & $79 \pm 6$ & $80 \pm 12$ \\
$\mathrm{~K}_{\mathrm{IC}}\left[\mathrm{x} 10^{6} \mathrm{~N} / \mathrm{m}^{3 / 2}\right]$ & $1.94 \pm 0.10$ & $1.83 \pm 0.07$ & $1.83 \pm 0.14$ \\
\hline
\end{tabular}

Load-CMOD curve. As regards the 3PBT, a slightly higher failure load is observed in case of SCC1 (see Table 1). However, given the larger scatter compared to the other concrete batches, the $F_{\max }$ differences are not really important. The maximum splitting forces of the WSTs do not remarkably diversify, either. Nevertheless, when considering the fracture energy and the fracture toughness of the 3PBTs, somewhat larger variations are present: the SCC2 beams seem the toughest and hardest to break, followed by the VC samples and the SCC1 specimens, respectively. Since SCC1 has got the highest w/c ratio (0.55 opposed to 0.45 in case of VC and SCC2) and thus the weakest cement paste, less energy is released during fracture and a smaller $\mathrm{K}_{\mathrm{IC}}$ value is noticed. The WST results reveal an altered mutual relationship between the three concrete types. Here, most energy is needed to split the VC specimens, which contain more coarse aggregate, whereas the SCC mixtures lack this large amount of bridging and toughening elements.
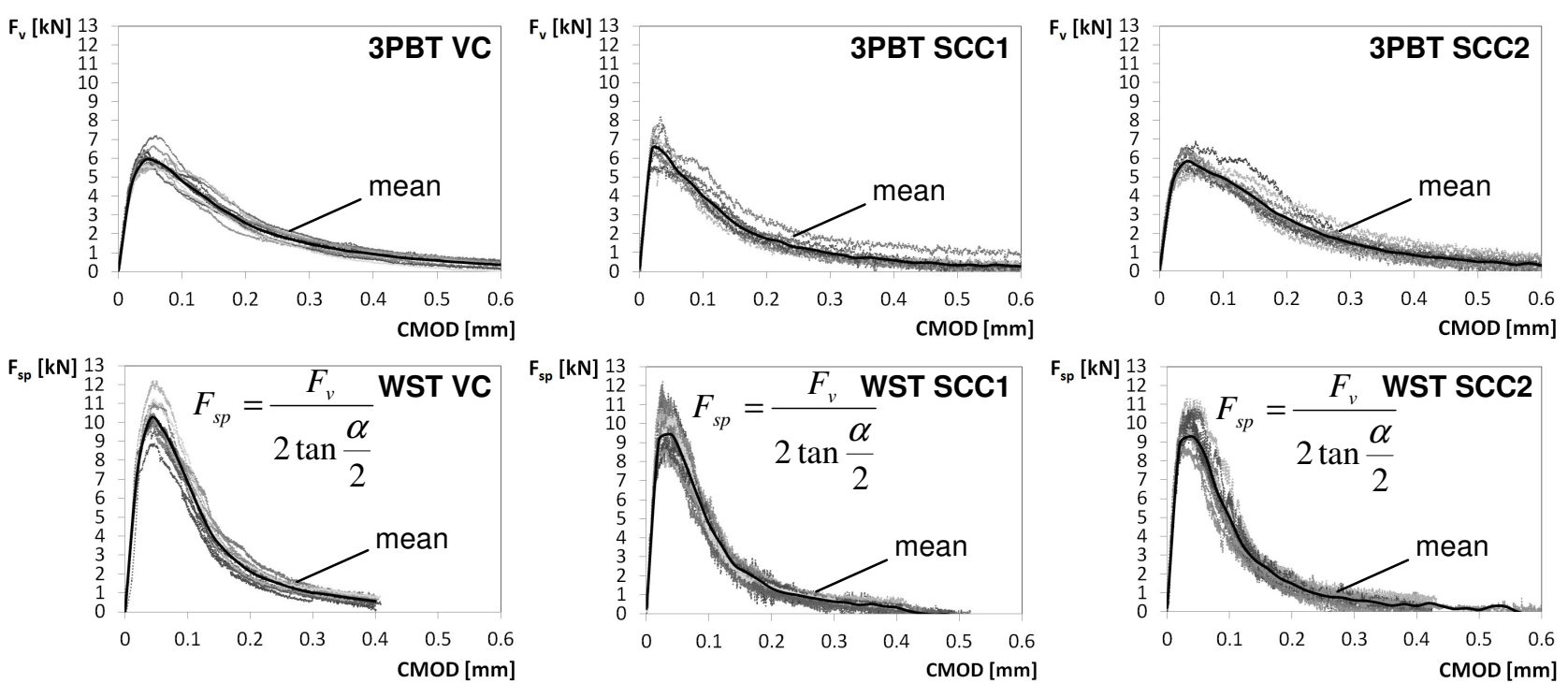

Fig. 3. Load-CMOD curves for $3 P B T$ and WST

Softening curve. The softening curves, derived from the 3PBTs (in the left of Fig. 4) show that SCC1 reaches its maximum stress at a lower crack width, consequently reducing the pre-peak 
energy release. Regarding the WSTs (right side of Fig. 4), good correspondence between the SCCs is found and most pre-peak damage occurs in case of $\mathrm{VC}$, with more fracture energy being released and more stresses being transmitted along the fracture process zone (FPZ). Notice for the three concrete types, that, once the load-carrying capacity is reached in the WST, the crack width does not increase as much as in the 3PBT.

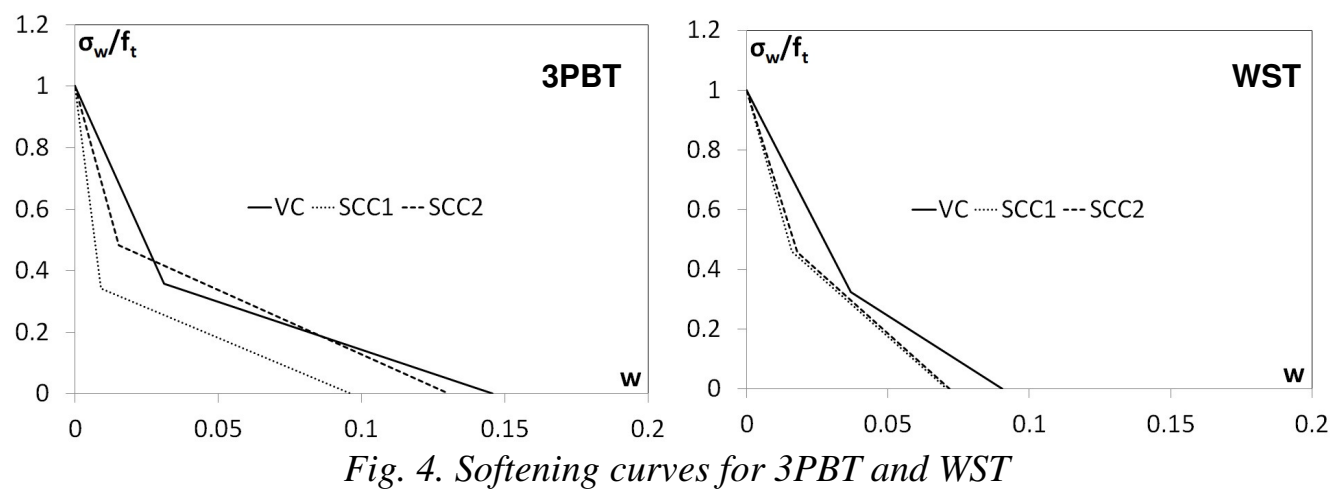

\section{Conclusion}

From the research, presented in this paper, it is clear that different results are obtained from the 3PBT and the WST. In case of the second experimental setup, it appears that the aggregate interlock plays the most important role in the cracking process, producing larger fracture parameter values for VC. The 3PBT, on the other hand, demonstrates a greater importance of the cement paste strength, which makes the SCC1 specimens (with the highest w/c ratio) the weakest and the least tough. Influencing factors for these differences are: a dissimilar specimen size, shape and self-weight, diverse FPZ length, varying stress states near the crack, and potential storage of elastic energy during testing. In any case, a distinct fracture behaviour is noticed, when comparing VC to SCC.

\section{Acknowledgments}

The authors wish to express their gratitude to the research fund University College Ghent for the financial support. OBC-Ottevaere is also thankfully acknowledged for the delivery of the concrete.

\section{References}

[1] De Schutter, G., Bartos, P., Domone, P., Gibbs, J. (2008). Self-Compacting Concrete, Whittles Publishing, Caithness, ISBN 978-1904445-30-2, 288 pages.

[2] De Schutter, G., Audenaert, K. (2007). In: Durability of Self-Compacting Concrete, State-of-theart report of RILEM Technical Committee 205-DSC, RILEM Report 38, pp. 185.

[3] De Schutter, G., Boel, V. (2007). In: Self-Compacting Concrete SCC2007, Proceedings of the Fifth International RILEM Symposium on SCC, RILEM Publications S.A.R.L., Proceedings PRO 54, 3 volumes, 1149 pages.

[4] de Oliveira e Sousa, J.L.A., Bittencourt, T.N. (2001). Experimental Analysis of Fracture Processes in Concrete, Journal of the Brazilian Society of Mechanical Sciences, Vol 23, No 4.

[5] Issa, M.A., Hammad, A.M., Chudnovsky, A. (1993). Correlation between Crack Tortuosity and Fracture Toughness in Cementitious Material, International Journal of Fracture, Vol 60, pp. 97-105.

[6] Löfgren, I., Olesen, J. F., Flansbjer, M. (2005). The WST-method for fracture testing of fibrereinforced concrete, Nordic Concrete Research, Vol. 34, No. 2, pp. 15-33. 